\title{
A Loculated Pyocele of Maxillary Sinus-A Rare Case Report
}

\author{
Ramanathan Thirunavukkarasu, Ganesh Kumar Balasubramaniam, \\ Ramesh Babu Kalyanasundaram, Paramaguru Rajesh Shanmugam \\ Department of ENT, Thanjavur Medical College \& Hospital, Thanjavur, India \\ Email: t.ramanathan.ent@gmail.com
}

Received 20 June 2014; revised 19 July 2014; accepted 18 August 2014

Copyright (C) 2014 by authors and Scientific Research Publishing Inc.

This work is licensed under the Creative Commons Attribution International License (CC BY). http://creativecommons.org/licenses/by/4.0/

(c) (i) Open Access

\begin{abstract}
Pyocele of maxillary sinus occurs unusually, when its mucocele content gets secondarily infected. Most of the pyocele occupies the frontal and anterior ethmoid sinus involving the frontal-ethmoidal complex expanding into the orbit leading to ocular disorders. Maxillary sinus presentation is rare, and our patient had a well defined loculated pyocele in her right maxillary sinus that we suspected with radiological images and was confirmed by needle aspiration under endoscopic guidance to the pyocele sac. Here we would like to describe more in detail about the nature of the mucopyocele in paranasal sinuses, its presentation and various surgical modalities of treating the pyocele.
\end{abstract}

\section{Keywords}

Loculated Pyocele, Maxillary Sinus, Mucocele, Endoscopic Marsupialization

\section{Introduction}

An infected mucocele is called a pyocele or muco-pyocele [1] and it develops more frequently in frontal and anterior ethmoidal sinuses than the posterior ethmoid, sphenoid or maxillary sinuses. The incidence of mucopyocele in general population is $0.4 \%-0.8 \%$ [2] that about only $10 \%$ of the mucopyoceles occur in the maxillary sinus [3]. Maxillary sinus pyocele usually presents as facial swelling of the involved side and with a vague headache. The frontoethmoidal, ethmoidal, sphenoidal and maxillary sinus pyocele are usually managed by endonasal micro-endoscopic surgery. External approach may also be combined with endonaal approach in cases of recurrence. We present one such case of mucopyocele in the posteromedial wall of right maxillary sinus of a 40-year-old female patient due to chronic infection managed by endoscopic marsupialization.

\section{Case Report}

A 40-year-old female patient presented with complaint of bilateral nasal obstruction with intermittent headache

How to cite this paper: Thirunavukkarasu, R., Balasubramaniam, G.K., Kalyanasundaram, R.B. and Shanmugam, P.R. (2014) A Loculated Pyocele of Maxillary Sinus-A Rare Case Report. International Journal of Otolaryngology and Head \& Neck Surgery, 3, 259-262. http://dx.doi.org/10.4236/ijohns.2014.35047 
for the past 20 years. History of Right sided facial pain present, History of reduced sense of smell present. No History of trauma, recurrent sneezing, nasal discharge or previous surgery. No history of visual disturbances. Anterior rhinoscopy revealed a deviated nasal septum to left side with hypertrophied inferior turbinate on right side. Examination of paranasal sinuses revealed tenderness in right maxillary sinus area.

Routine blood investigations are within normal limits, CT paranasal sinuses revealed a well defined homogenous opacity in the posteromedial wall of right maxillary sinus (Figure 1 and Figure 2).

On considering the patient's age and a long standing history of nasal obstruction and headache we suspected a pyocele of chronic infective cause although a differential diagnosis of odontogenic cyst, tumor was also considered.

The patient was taken up for surgery. Under local anaesthesia submucosal resection with spurrectomy was done. Under guidance of zero degree $4 \mathrm{~mm}$ Hopkins rod, middle meatal antrostomy was done on right side to approach the pyocele. Later inferior meatal antrostomy was also done using myle's gouge to gain better access to the pyocele and it was found to be located in the posteromedial wall of right maxillary sinus, confirmed by needle aspiration. About $5 \mathrm{ml}$ of pus was drained and the pyocele sac incised and marsupialized. Stripping of the mucopyocele lining was not done, because the epithelium returns to normal postoperatively [4] (Figure 3 and Figure 4).

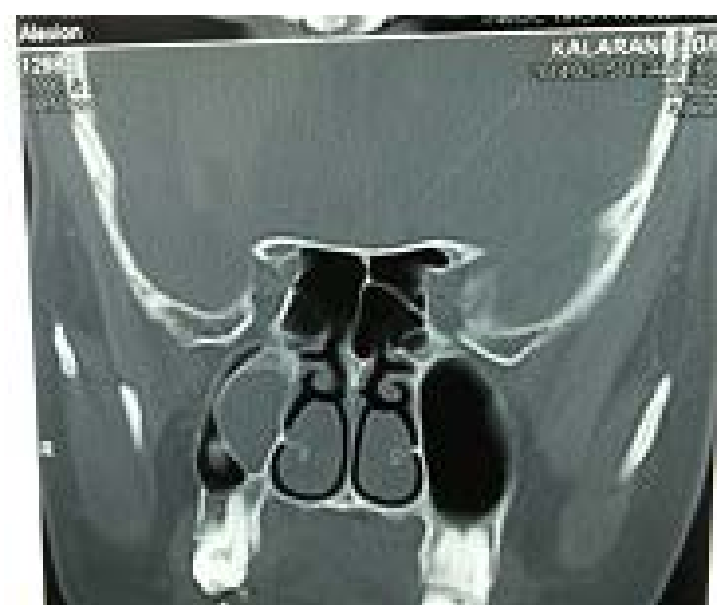

Figure 1. Preoperative CT picture showing the pyocele sac with its wall attached to the medial wall of the right maxillary sinus.

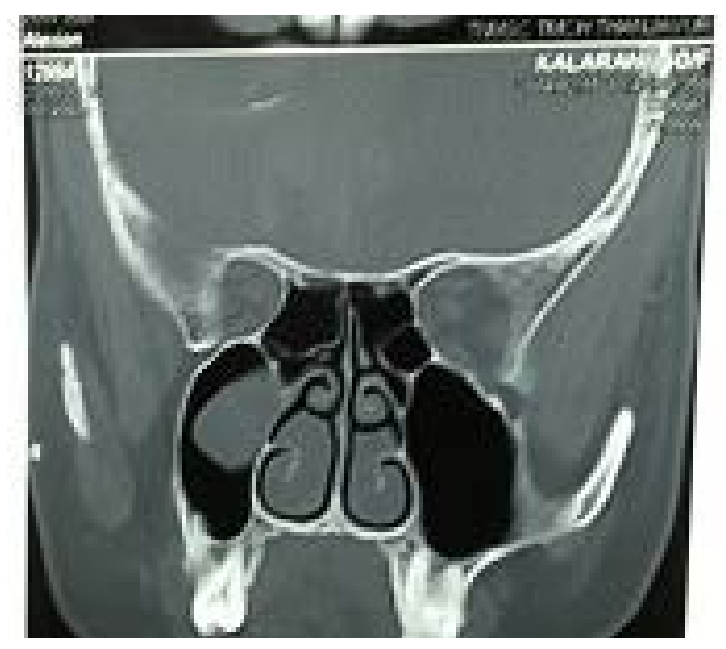

Figure 2. An another preoperative CT picture showing the pyocele sac attached to the posteromedial wall of the right maxillary sinus. 


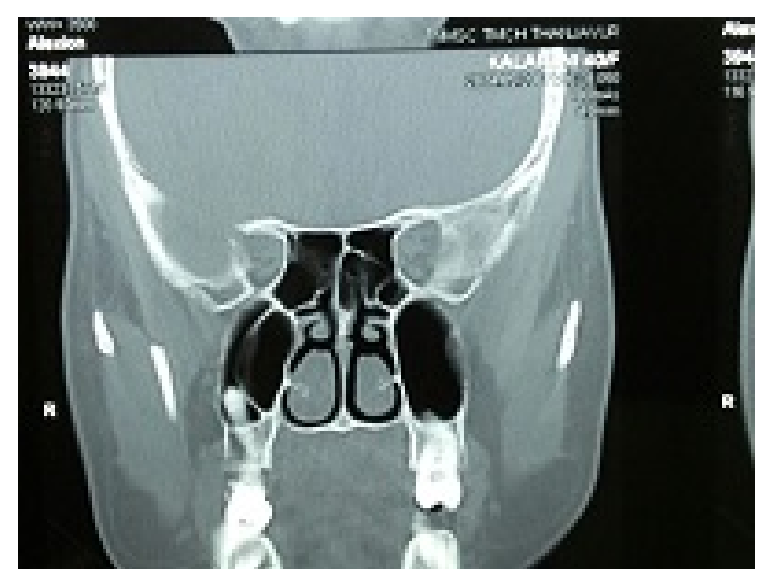

Figure 3. Postoperative CT picture showing right maxillary sinus with shadows of pyocele lining as we haven't stripped the lining of the pyocele. We marsupialized the wall of the pyocele sac.

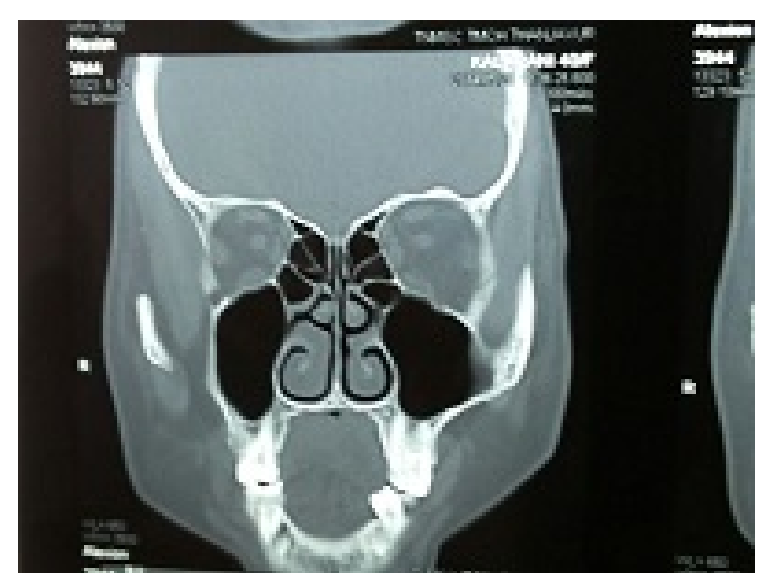

Figure 4. Postoperative CT picture showing a clear right maxillary sinus.

\section{Discussion}

A mucocele of paranasal sinus is a slowly expanding epithelium-lined lesion containing inspissated mucus that fills the sinus cavity, and is formed when its draining mucus gets blocked by an obstruction at it ostium. The obstruction to the outflow may be due to chronic inflammation, post surgery, radiotherapy, trauma and tumors [4]. Some of the lesions of the maxillary sinus result from allergy, inflammation and malignancy others occur after surgery, particularly after a Caldwell-luc procedure [3].

In the formation of mucoceles there is true bone destruction owing to its expansive character. In the previous studies it had been found that mucocele tissue synthesises more prostaglandin E2 than normal tissue. This leads to elevated levels of cytokines (interleukin E, Tumor Necrosis factor- $\alpha$, Vascular adhesion factor). These cytokines are responsible for destruction with consequent reabsorption, rarefaction and local bone expansion facilitating their widening [2]. The most common clinical manifestation of a mucopyocele of the maxillary sinus is facial swelling. The most common ocular manifestation of mucopyocele of maxillary sinus is upward displacement of eye ball [3]. Destruction of the roof of the maxillary antrum allows expansion of the mucocele into the orbital cavity, with elevation of the globe and proptosis. Unilateral or bilateral proptosis may also occur in patients with pyoceles of the sphenoid sinus. One or both abducent nerves may be affected in pyocele of sphenoid sinus. Compression of contiguous structures within the orbit may result in diplopia on attempted downward gaze. Rarely sphenoethmoidal pyocele may compress both optic nerves producing bilateral progressive visual loss [3]. The patient we reported presented with right sided facial swelling and right sided facial pain without any ocular 
abnormalities or visual disturbances. With the clinical and radiological evidences we planned for surgery. It is the treatment of choice and can be done either by external or endoscopic approach. Endonasal approach is effective to treat mucopyoceles [5]. Frontoethmoidal, ethmoidal, sphenoidal and maxillary sinus mucopyocele are excellent indications for exclusive endonasal micro-endoscopic surgery. The osteoplastic approach combined with endonasal surgery is suitable for laterally located frontal or maxillary sinus mucopyoceles [6]. An external approach combined with endoscopic surgery is suitable in frontal mucoceles especially in distal sites and in case of recurrence [7]. Doing Middle Meatal Antrostomy (MMA) in maxillary sinus pyocele significantly reduces the recurrence rate [8]. Hence endoscopic marsupialization is considered a safe and effective approach with less postoperative complications and we proceeded with it and the post operative period was uneventful. The patient is under regular follow up and is symptom free without any evidence of recurrence.

A bacteriological swab taken from the pus inside the sac revealed growth of Gram positive cocci (staph albus \& strep viridians) in the culture.

\section{Conclusions}

Pyocele of maxillary sinus being an uncommon diagnosis should be considered in case of any well defined homogenous/heterogenous opacity inside the sinus, which can be confirmed with needle aspiration or culture.

Surgery with endonasal approach being a safe and effective procedure with less recurrence rate as the MMA with endoscopic marsupialization abolishes middle meatal obstruction and establishes better drainage and ventilation of the maxillary sinus and restitution of its mucosa [9]. It is also considered that Inferior Meatal Antrotomy (IMA) done simultaneously with MMA is a beneficial complementally surgical procedure as we did in this patient [10].

\section{References}

[1] De, S.K. (1996) A Case of Muco-Pyocele of the Maxillary Antrum Simulating Malignant Neoplasm. Cambridge Journal of Laryngology \& Otology, 80, 548-552.

[2] Kshar, A., Abijeetpatil, Umarji, H. and Kadam, S. (2014) Mucopyocele of Maxillary Sinus. Dental Research Journal, 11, 119-123.

[3] Miller, N.R., Newman, N.J., Walsh, F.B. and Hoyt, W.F. (2005) Mucoceles, Pyocele, Sinusitis. Walsh \& Hoyt's Clinical Neuroophthalmology, 3, 2611-2618.

[4] Bhandary, S.K., Bhat, V.S. and Khana, R.A. (2013) Frontal Sinus Mucocele Following Facial Trauma Presenting a Pyocele. NUJHS, 3, 90-92. http://nitte.edu.in/journal/March2013/FSFATF.pdf

[5] Almedia, W.L.C., Martin, L.R.L., Perazzo, P.S.L., Lima, M.R. and Rados, C. (2004) Maxillary Sinus Mucopyocele with Facial Asymmetry. International Archives of Otorhinolaryngology, 8. http://www.internationalarchivesent.org/additional/acervo_eng.asp?id=266

[6] Bockmuhl, U., Kratzsch, B., Bendak, et al. (2005) Paranasal Sinus Mucoceles: Surgical Management \& Longterm Results. NCBI, 84, 892-898.

[7] Peric, A., Milojevic, M., Ljubicic, A. and Sotirovic, J. (2009) Endoscopic Middle Meatal Antrostomy in Treatment of Maxillary Sinus Mucoceles. VSP (Vojno Sanitetski Pregled), 66, 207-211.

[8] Huang, C.C., Chen, C.W., Lee, T.J., et al. (2011) Transnasal Endoscopic Marsupialization of Post Operative Maxillary Mucocele: MMA vs IMA. European Archives of Oto-Rhino-Laryngology, 268, 1583-1587.

[9] Peric, A., Milojevic, M. and Ljubicic, A. (2009) Endoscopic Middle Meatal Antrostomy in Treatment of Maxillary Sinus Mucoceles. Vojnosanitetski Pregled, 66, 207-211.

[10] Venail, F., Marlier, F., Makeieff, M., et al. (2003) Combined Approach (Endoscopic \& External) for the Treatment of Sinonasal Mucoceles. Revue de Laryngologie Otologie Rhinologie, 124, 165-170. 
Scientific Research Publishing (SCIRP) is one of the largest Open Access journal publishers. It is currently publishing more than 200 open access, online, peer-reviewed journals covering a wide range of academic disciplines. SCIRP serves the worldwide academic communities and contributes to the progress and application of science with its publication.

Other selected journals from SCIRP are listed as below. Submit your manuscript to us via either submit@scirp.org or Online Submission Portal.
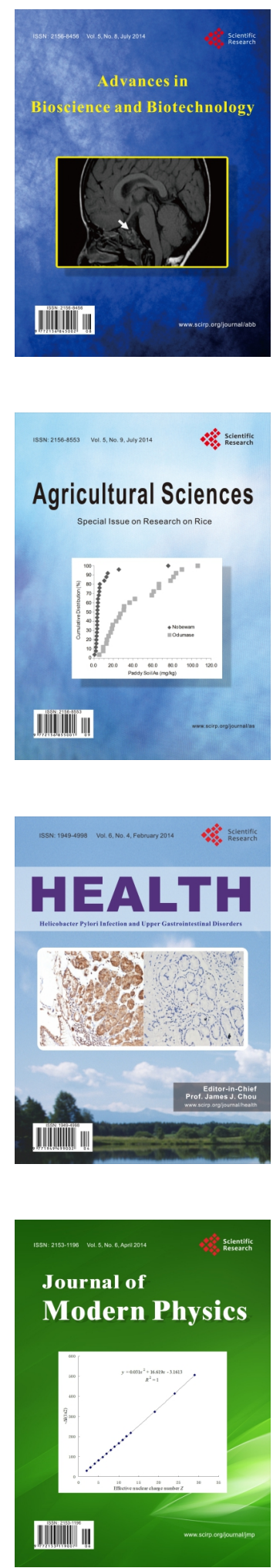
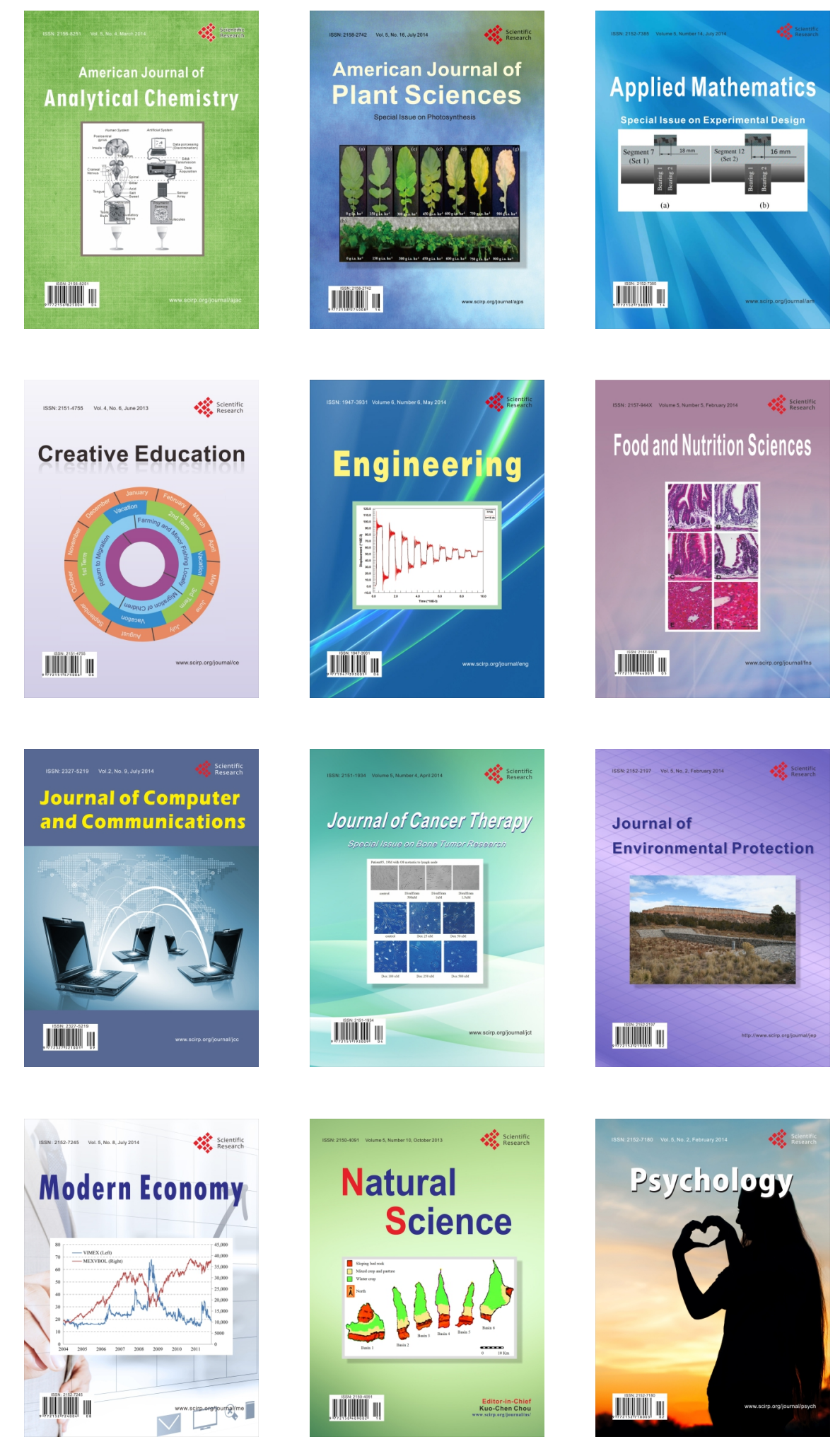